\title{
Secondary prevention: improving outcomes following myocardial infarction
}

\author{
Aldo P Maggioni
}

In the first five years of the 1990s, the role of angiotensin converting enzyme (ACE) inhibitors in the treatment of patients with myocardial infarction was investigated in a series of large controlled trials involving more than 100000 patients (table 1$)^{1}$

The early use of ACE inhibitors after acute myocardial infarction (MI) has been investigated in four trials (CONSENSUS II, GISSI 3, ISIS 4, and CCS 1) involving more than 98000 patients with treatment initiated within 24-36 hours from the onset of MI symptoms. ${ }^{2-5}$

Five of the trials (SAVE, AIRE, TRACE, and SOLVD prevention and treatment trials) involving a total of over 11000 patients investigated the effects of late treatment with ACE inhibitors in patients with left ventricular dysfunction or failure. ${ }^{6-10}$

\section{Early unselected trials}

An overview of the early, unselected trials showed that 30 days after MI, patients allocated to ACE inhibitors had a significant reduction in mortality from $7.6 \%$ to $7.1 \%$ $(p=0.004)$, which corresponds to five lives saved per 1000 patients treated. ${ }^{11}$

In addition, there was a significantly lower rate of non-fatal congestive heart failure episodes, with a reduction from $15.2 \%$ among patients allocated to control, to $14.6 \%$ among patients allocated to ACE inhibitors $(p=0.01)$. This corresponds to the prevention of six cases of non-fatal heart failure per 1000 patients treated. ${ }^{11}$

Unexpectedly, the benefit of ACE inhibitors was achieved very early after the start of treatment; 239 fewer deaths were observed during the first 30 days in the group receiving ACE inhibitors than among those patients allocated to control. Of these 239 deaths, 200 were saved in the first week after the beginning of treatment and the onset of symptoms. This means that more than $80 \%$ of the benefit achieved with this strategy was achieved in the first week after the onset of MI symptoms. ${ }^{1}$

Long term follow up data from the GISSI-3 trial show that the early benefit of ACE inhibitors was maintained over a long period of time.

Table 1 Trials with ACE inhibitors in patients with acute myocardial infarction. Over five years, more than 100000 patients with acute MI were randomised to ACE inhibitors

\footnotetext{
ANMCO Research Centre, Via La Marmora 34, 50121 Firenze, Italy A P Maggioni

Correspondence to: Dr Maggioni
} email: maggioni@anmco.it

\begin{tabular}{lcll}
\hline \multicolumn{2}{l}{ Four early unselected trials } & \multicolumn{2}{l}{ Five late selected trials } \\
\hline CONSENSUS-2 & 6090 & SAVE & 2231 \\
GISSI-3 & 19394 & AIRE & 1986 \\
ISIS-4 & 58050 & TRACE & 1749 \\
CCS-1 & 14962 & SOLVD-P & 3882 \\
& & SOLVED-T & 1687 \\
Subtotal & 98496 & Subtotal & 11035 \\
& Total & 109531 & \\
\hline
\end{tabular}

The benefits achieved after six weeks were still present four years later: eight lives saved per thousand at six weeks, five lives saved per thousand at six months, and nine lives saved per thousand at four years. ${ }^{12}$

\section{Late selected trials}

There were three key studies looking at the use of ACE inhibitors some days after MI in patients with left ventricular dysfunction or heart failure: SAVE, AIRE, and TRACE..$^{6-8}$

The SAVE trial randomised more than 2000 patients with an ejection fraction $<40 \%$ to captopril or placebo. ${ }^{6}$ The AIRE trial selected patients on the basis of clinical heart failure and approximately 2000 patients were randomised to ramipril or placebo. ${ }^{7}$ And finally, the TRACE trial randomised patients to trandolapril or placebo if an echocardiographic evaluation of wall motion corresponded to an ejection fraction of $\leqslant 35 \%{ }^{8}$

A recent overview of these trials showed that mortality was significantly reduced from $26.5 \%$ to $22.1 \%(\mathrm{p}=0.00001)$ in patients receiving ACE inhibitors. In absolute terms this corresponds to 44 lives saved per 1000 patients treated, which is highly significant. Similarly, the risk of reinfarction was reduced from $12.2 \%$ to $10.2 \% \quad(p=0.0004)$, corresponding to 20 reinfarctions prevented per 1000 patients treated. ${ }^{1}$

\section{Clinical implications}

WHEN TO TREAT?

There is no evidence of a time related benefit of ACE inhibitors. However, mechanistic studies have shown that early treatment reduces infarct expansion and ventricular enlargement. In addition, a review of the early trials shows that more than $80 \%$ of the total benefit of ACE inhibitors is achieved in the first week after the onset of symptoms ${ }^{11}$ (fig 1). The benefit achieved in the first few days after acute $\mathrm{MI}$ is maintained over at least four years ${ }^{12}$ (fig 2). It is therefore important not to miss the opportunity to save lives because of unnecessary delays.

\section{WHO TO TREAT?}

The overview of the early, unselected trials shows that the mortality reduction was similar among all the subgroups in the studies. In terms of adverse reactions, the risk of hypotension and renal dysfunction was similar in patients at different levels of risk, except in older patients ( $\geqslant 75$ years). ${ }^{11}$

With the exception of elderly patients, predictors of an increased risk of death such as prior MI, diabetes, anterior MI location, and 


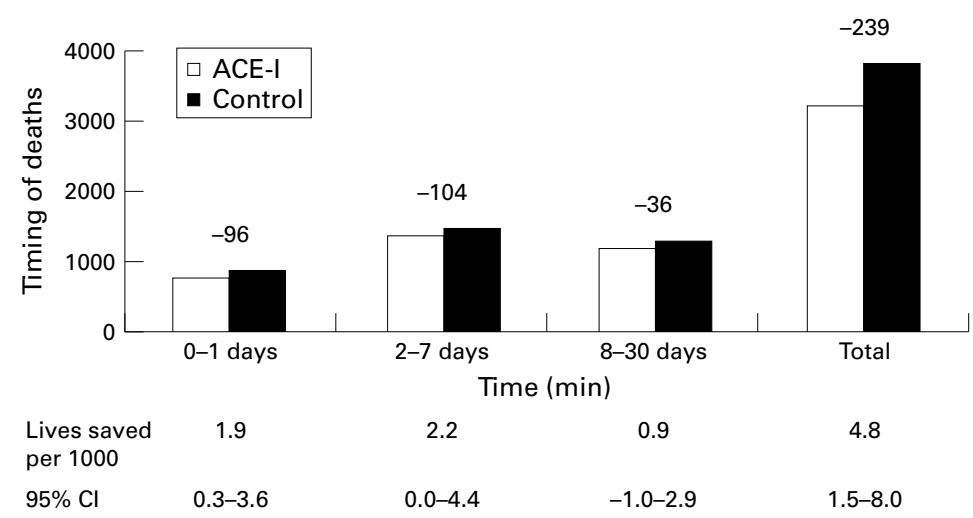

Figure 1 Timing of deaths in first 30 days following treatment.

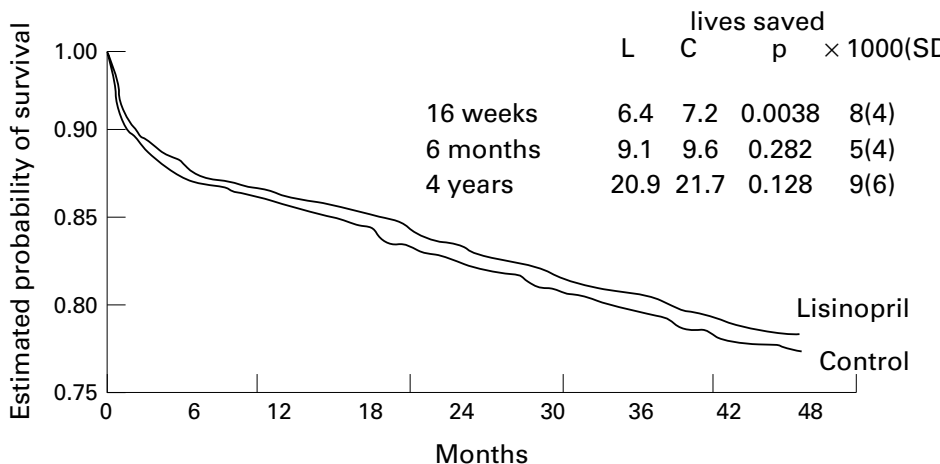

Figure 2 Estimated probability of survival up to four years following lisinopril or placebo treatment. practice. The study showed that ACE inhibitors for the treatment of myocardial infarction in the acute phase $(<24$ hours) are clearly underused with an actual use of only $39 \%$ compared with an expected use of $70 \%$ (Latin Survey presented at the Cardiac Emergency Strategies for Y2K, Rome, Italy, October 15, 1999).

With respect to the secondary prevention strategies, ACE inhibitors are recommended in $38 \%$ of patients with left ventricular dysfunction. The rate of use of this drug was more than expected with $57 \%$ actual use. ${ }^{14}$

HOPE STUDY

Until recently there were no definitive data with respect to the effect of ACE inhibitors in post-MI patients without heart failure and with preserved left ventricular function. However, at the 21st congress of the European Society of Cardiology in 1999, important new data from the HOPE study on the use of ACE inhibitors in patients at high risk of cardiovascular events were presented for the first time. ${ }^{15}$

The HOPE study was a large scale, four year, randomised, double blind, placebo controlled study to evaluate ramipril and vitamin $\mathrm{E}$ in 9541 patients. Patients at high risk of developing a major cardiovascular event were included, defined as those with a history of vascular disease, or with diabetes plus one other coronary risk factor. Patients were excluded if they had heart failure or a low ejection fraction, were already taking an ACE inhibitor or vitamin E, or had an acute event in the previous four weeks.

There was a significant reduction of the composite end point of MI, stroke, and cardiovascular death from $17.5 \%$ among patients randomised to placebo, to $13.9 \%$ among those randomised to ACE inhibitors. The reduction is approximately $22 \%$ and is highly significant $(p=0.000002)$. This benefit is also seen in all the subgroups of patients.

Importantly, these results were obtained on top of the other recommended treatments. At the beginning of the trial, about $75 \%$ of patients were treated with antiplatelets; lipid lowering was used in $29 \%$ of patients; $\beta$ blockers were used in 39\%; diuretics in $15 \%$; and calcium channel blockers in $47 \%$.

There is overwhelming evidence from HOPE that ACE inhibitors prevent cardiovascular deaths, stroke, MI, and heart failure, and reduce the rate of hospital admission for revascularisation. There is the interesting observation that in non-diabetic patients allocated to ramipril, there was a reduced rate of diabetes development in comparison with placebo. Moreover, diabetic microvascular complications were significantly reduced in the ACE inhibitor group. These benefits are consistently observed in a very broad range of high risk patients and in addition to other effective treatments. The only adverse event was cough, which was observed in 5\% more patients in the ACE inhibitor group than in the placebo group.
A survey in the first three months of 1999 among Italian patients looked at how evidence based recommendations translate into clinical 


\section{Trial acronyms}

AIRE: Acute Infarction Ramipril Efficacy

CCS 1: Chinese Cardiac Study 1

CONSENSUS II: Co-operative North Scandinavian Enalapril Survival Study

EUROPA: European trial on Reduction Of cardiac events with Perindopril in stable coronary Artery disease

GISSI 3: Gruppos Italiano per lo Studio Sella sopravvivenza nell'Infarcto miocardico

HOPE: Heart Outcomes Prevention Evaluation

ISIS 4: Fourth International Study of Infarct Survival

PEACE: Prevention of Events with Angiotensin-Converting Enzyme inhibition

SAVE: Survival and Ventricular Enlargement

SOLVD: Studies of Left Ventricular Dysfunction

TRACE: Trandolapril Cardiac Evaluation

\section{Ongoing trials}

HOPE is not the only trial testing the hypothesis of treating coronary patients without left ventricular dysfunction or heart failure. There are at least two further ongoing trials testing this hypothesis in patients at lower risk than those randomised in HOPE: PEACE and EUROPA. ${ }^{16} 17$

The PEACE trial is recruiting over 8000 patients and is comparing trandolapril with placebo. ${ }^{14}$ All patients have well documented coronary heart disease and an ejection fraction higher than $40 \%$. The primary end point is $\mathrm{MI}$, cardiovascular death, and the rate of revascularisation procedures. The follow up is 5.5 years.

The EUROPA trial is looking at perindopril versus placebo in more than 10000 patients. ${ }^{15}$ All patients have well documented coronary artery disease. End points include death and MI. The follow up is 3.75 years.

\section{Conclusion}

Long term ACE inhibitor treatment is strongly recommended in patients with documented coronary artery disease and when these patients show clinical signs or symptoms of heart failure and left ventricular dysfunction. The HOPE trial supported the indication of long term ACE inhibitor treatment of all patients at high risk of cardiovascular events. However, at least one of the two ongoing trials, PEACE and EUROPA, should be completed before a definite conclusion about the use of ACE inhibitors for all patients with coronary artery disease, or who are at high risk, is reached.

1 Maggioni AP. ACE inhibitor treatment after myocardial infarction. Eur Heart $\mathcal{F}$ Suppl 1999;1(suppl Q):Q7-10.

2 The CONSENSUS Trial Study Group. Effects of enalapril on mortality in severe congestive heart failure: results of the co-operative north Scandinavian enalapril survival study co-operative north Scandinavian enalapril survival
(CONSENSUS). N Engl f Med 1987;316:1429-35.

3 Gruppo Italiano per lo Studio della Sopravvivenza nell'Infarto Miocardico. GISSI-3: effects of lisinopril and transdermal glyceryl trinitrate singly and together on 6-week mortality and ventricular function after acute myocardial infarction. Lancet 1994;343:1115-2.

4 ISIS-4 Collaborative Group. ISIS-4: a randomised factorial trial assessing early oral captopril, oral mononitrate, and intravenous magnesium sulphate in 58,050 patients with suspected acute myocardial infarction. Lancet 1995;345: 669-85.

5 Chinese Cardiac Society Collaborative Group. Oral captopril versus placebo among 13634 patients with suspected pril versus placebo among 13634 patients with suspected acute myocardial infarction: interim report from the

6 Pfeffer MA, Braunwald E, Moye LA, et al. Effect of captopril on mortality and morbidity in patients with left ventricular dysfunction after myocardial infarction. $N$ Engl Med 1992;327:669-77.

7 The Acute Infarction Ramipril Efficacy (AIRE) Study Investigators. Effect of ramipril on mortality and morbidity of survivors of acute myocardial infarction with clinical evidence of heart failure. Lancet 1993;342:821-8.

8 Kober L, Torp-Pedersen C, Carlson JE, et al. A clinical trial of the angiotensin converting enzyme inhibitor trandolapril in patients with left ventricular dysfunction after myocardial infarction. Trandolopril cardiac evaluation (TRACE) study group. N Engl F Med 1995;333:1670-6.

9 The SOLVD Investigators. Effect of enalapril on mortality and the development of heart failure in asymptomatic patients with reduced left ventricular ejection fractions. $N$ Engl f Med 1992;327:685-91.

10 The SOLVD Investigators. Effect of enalapril on survival in patients with reduced left ventricular ejection fractions and congestive heart failure. $N$ Engl F Med 1991;325:293-302.

1 ACE Inhibitor Myocardial Infarction Collaborative Group. Indications for ACE inhibitors in the early treatment of acute myocardial infarction. Systematic overview of individual data from 100,000 patients in randomized trials. Circulation 1998;97:2202-12.

12 Tavazzi L. GISSI-3: long-term follow-up. Circulation 1999; 99:1128.

13 Franzosi M G, Maggioni A P, Santoro E et al. Costeffectiveness analysis of early lisinopril use in patients with acute myocardial infarction. Results from GISSI-3 trial. Pharmacoeconomics 1998;13:337-46..

14 Maggioni AP, Tavazzi L, Fabbri G, et al for the GISSI-Prognosis Investigators. Epidemiology of postnfarction risk stratification strategies in a country with a ow volume of revascularization procedures. The GISSIPrognosis Registry. Eur Heart f 1998:19:1784-94.

15 The Heart Outcomes Prevention Evaluation Study Investigators. Effects of an Angiotensin-converting-enzyne inhibitor, ramipril, on cardiovascular events in high-risk patients. N Engl F Med 2000;342:145-53.

16 Pfeffer MA, Domanski M, Rosenberg Y, et al. Prevention of events with angiotensin-converting enzyme inhibition (the PEACE study design). Prevention of events with angiotensin-converting enzyme inhibition. $A m \mathcal{F}$ Cardiol 1998;82:25H-30H.

17 Fox KM, Henderson JR, Bertrand ME, et al. The European trial on reduction of cardiac events with perindopril in stabel coronary artery disease (EUROPA). Eur Heart 7 1998; 19(suppl J):J52-5. 